\title{
Numerical and experimental analysis of balloon angioplasty impact on flow hemodynamics improvement
}

\author{
Michą TOMASZEWSKI ${ }^{1}$, KAMIL SYBILSKI ${ }^{1}$, JERZY MAŁACHOWSKI ${ }^{1 *}$, \\ WOJCIECH WOLAŃSKI ${ }^{2}$, PIOTR P. BUSZMAN ${ }^{3}$ \\ ${ }^{1}$ Military University of Technology, Faculty of Mechanical Engineering, Warsaw, Poland. \\ ${ }^{2}$ Silesian University of Technology, Faculty of Biomedical Engineering, Gliwice, Poland. \\ ${ }^{3}$ Andrzej Frycz-Modrzewski Krakow University, Department of Cardiology, \\ Center for Cardiovascular Research and Development American Heart of Poland, Kraków, Poland.
}

\begin{abstract}
Purpose: The paper focuses on the numerical and experimental evaluation of the fluid flow inside chosen fragments of blood vessels. In the first stage of the study, the experimental tests were conducted using a research test stand, designed to be used in this evaluation. The study evaluated the blood flow through a silicone vessel with an implanted coronary stent. Methods: The PIV method was used in order to visualize the flow vectors inside a silicone vessel. Deformed vessel geometry implemented for computational fluid dynamics purposes was obtained owing to a non-linear simulation of the stent expansion (angioplasty process) in a silicone vessel. Additionally, a vessel model with a statistical $55 \%$ area stenosis and an irregular real vessel with an atherosclerotic plaque were also subjected to analysis from the hemodynamic flow point of view. A vessel with a statistical stenosis was also used to simulate the angioplasty process, which resulted in obtaining a flow domain for the vessel with an atherosclerotic plaque after the stent implantation. Results: For each case, distributions of parameters such as OSI or TAWSS were also analyzed and discussed. The areas of low TAWSS values appear close to the stent struts. Conclusions: Stents with increased diameters, compared to the normal vessel diameter, create a higher risk of occurrence of the areas with low WSS values. Excessive stent deformation can cause inflammation by injuring the vessel and can initiate the restenosis and thrombotic phenomena through the increased vessel diameter.
\end{abstract}

Key words: angioplasty, stent, artery, hemodynamics, cfd analysis, PIV method

\section{Introduction}

Constant progress of manufacturing methods and materials for stents significantly improves their effectiveness in the organism [18]. The problem which has not yet been fully diagnosed is the vessel restenosis caused by the neointima overgrowth. Except for vessel wall injury caused by stent implantation, this phenomenon is caused by systemic factors such as diabetes or endothelial dysfunction [10]. Some sources point out that the restenosis could be caused by gene polymorphism [22]. Many studies show that the restenosis is caused by hemodynamic factors of the blood flow [4], [8], [18], [19]. Hemodynamic problem was studied in numerous papers [1], [23]. The main aim of the paper [23] was to evaluate the performance of different stent structures by characterizing the mechanical parameters after coronary stenting. The authors analysed six stent structures due to determine local hemodynamics and mechanical parameters. A lower value of time average wall shear stress (TAWSS) was localised at sites around struts and links near the ends of the stent. The effects of strut spacing, thickness, luminal

* Corresponding author: Jerzy Małachowski, Institute of Mechanics and Computational Engineering, Military University of Technology, Faculty of Mechanical Engineering, ul. Gen. Sylwestra Kaliskiego 2, 00-908 Warsaw, Poland. Phone: +48261839140 , e-mail: jerzy.malachowski@wat.edu.pl

Received: May 25th, 2020

Accepted for publication: July 13h, 2020 
protrusion, and malapposition were analysed in [1]. Larger spacing between struts has a beneficial effect on the flow and an adverse effect of larger strut size appears to be reduced in combination with larger strut spacings [1]. In [19], the presence and potential consequences of flow turbulences, both in the ascending aorta and arch after a stenting left main (LM) mid shaft or distal disease, were investigated. LM stenting produced alterations of the fluid dynamic into the ascending aorta and the arch, and induced more turbulence in the LM and in the aortic wall. In this work, flow analysis of artificial vessels with an implemented intravascular stent was performed. The stent geometry has a huge impact on the flow character. The fluid inside the vessel hits many small obstacles, such as stent struts, causing flow irregularities leading to small oscillatory shear stress, which may cause the neoatherosclerotic plaque development, thrombosis and restenosis [9], [11]. Using the computer aided fluid mechanics, it is possible to evaluate an influence of the stent geometry on the flow character. This method also allows for visualization of the spots with either high or low values of shear stress. While analysing the hemodynamic processes, it is important to verify the WSS (Wall Shear Stress) values [23].

The endothelial cells with WSS higher than $1.0 \mathrm{~Pa}$ tend to elongate in the direction of the flow, while the cells with WSS lower than $0.4 \mathrm{~Pa}$ are more round and have no directional tendency [15]. Those round cells, together with blood stagnation typically observed in vessel areas with low WSS values, lead to an increased penetration of blood-related particles into the vessel walls. This phenomenon is often associated with the development of the vessel atherosclerosis and is a consequence of the increased time when the particles interact with the wall and with an increased permeability of the endothelium. The authors demonstrated that the tissue growth in the artery with the implemented stent was noticeable in fragments with low WSS [12]. The influence of this stress is described in works [5], [13]. Another parameter characterizing the flow hemodynamic is the OSI (Oscillatory Shear Index) which varies from 0.0 (no oscillatory WSS) to 0.5 (maximal WSS recorded). Areas with high OSI values (exceeding 0.1 value) in arteries with an implanted stents are more prone to occurrence of neointima overgrowth [24].

Based on the performed studies, the method of the study and the obtained results, in which the flow velocity vector distributions were compared for a silicone vessel with a stent implanted through the balloon angioplasty procedure, can be regarded as original to the article. Hemodynamic factors distribution for different vessel geometries were also analysed and compared.

\section{Materials and methods}

\subsection{Experimental testing}

The experimental tests were conducted on a research test stand (Fig. 1) designed purposely for the flow evaluation and allowing for simulating the blood flow in coronary vessels. Medical pressure sensors were used in front of and behind the measured segment in order to read the pressure values. A flow sensor was used to register the flow rate. Two throttling valves were used to control the flow imposed by a peristaltic pump, which allowed for analysis of the flow corresponding to different heart beat parameters. The PIV method was used to determine the velocity vectors. This method uses a laser generating a series of double impulses. When the laser beam hits the optical system, it is converted into an elongated beam called a laser blade. This beam then illuminates the seeding particles suspended in the fluid. The particles are coated in the rhodamine type B [21]. The whole setup is mounted on a designed frame structures which allows for different vessel positioning. The frame with the measured segment is submerged in a reservoir. Silicone tubes with diameter $D_{z}=3.2 \mathrm{~mm}$ and wall thickness $d=0.75 \mathrm{~mm}$ with stents were used in the study. A detailed description presenting all technical and methodological aspects are presented in paper [21].

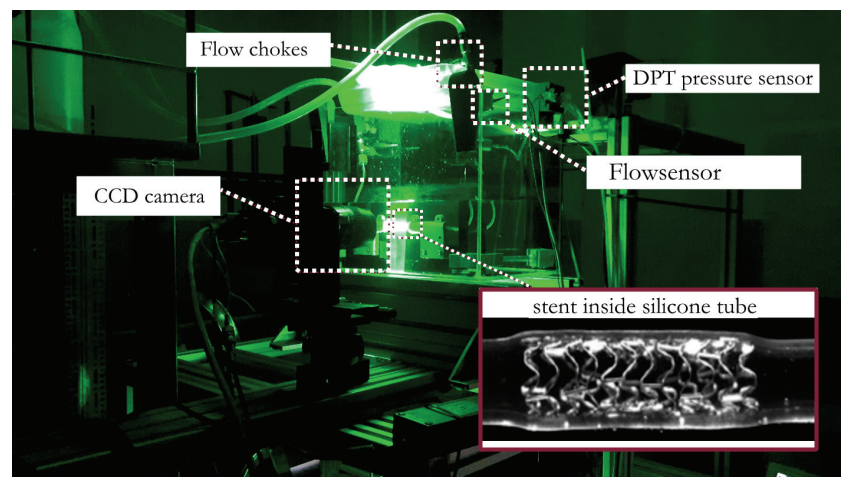

Fig. 1. Research test stand used to study the fluid flow

\subsection{Numerical studies}

The study shows different numerical models divided into two groups. The first group contained the model of the case used in the experimental tests and reflected both the initial and the boundary conditions for validation aims. The second group con- 
tained 3 numerical models: a vessel with a statistical stenosis, vessel with a real stenosis and a vessel with a statistical stenosis after performed stent implantation. At the initial stage of those investigations, several meshes with different mesh sizes were tested and validated using theoretical studies for simple pipes as well as using experimental methods with the PIV method implementation for pipes with and without stents. Finally, validated and elaborated mesh sizes were adopted in the presented cases. For those cases, the numerical simulations used the pressure and flow intensity characteristics obtained from the literature [7].

\subsubsection{Numerical model: modelling of the experimental case}

For the case in which the flow in a tube with a stent was analysed, a non-linear analysis of the balloon expansion inside a straight silicone tube was conducted [3]. The dimensions of the tube were assessed using photos taken during the experiment. A cylinder was created and filled with finite volumes repre- senting the volume of the fluid inside the tube (Fig. 2). The inserted coronary stent was made from a cobaltchrome alloy. It was decided to perform a numerical simulation, similar to experimental tests, with the use of computational fluid dynamics (CFD). In order to perform such an analysis, it was first necessary to perform a structural numerical analysis of the modelled stent expansion inside the modelled silicone tube in order to obtain a geometrical representation of the stent and the tube after implementation. To achieve this, a stent numerical model was developed, similar to the one used during the experimental study for the simulation of the angioplasty process (Fig. 3).

With the use of the triangle finite elements, the internal geometry of the model was detached to a function as a boundary condition while developing the finite element flow domain (Fig. 4). The domain contained 7113349 finite volumes. In the areas close to the stent and vessel walls, the elements with increasing dimensions (from the smallest $-0.005 \mathrm{~mm}$ - to the highest $-0.07 \mathrm{~mm}-$ in the direction to centre of the vessel) were used to increase the accuracy of the fluid velocity profile simulation. To map the areas close to the vessel walls, a smooth transition of the elements size was used in order to maintain the $\mathrm{Y}+\sim 1$ parameter, which

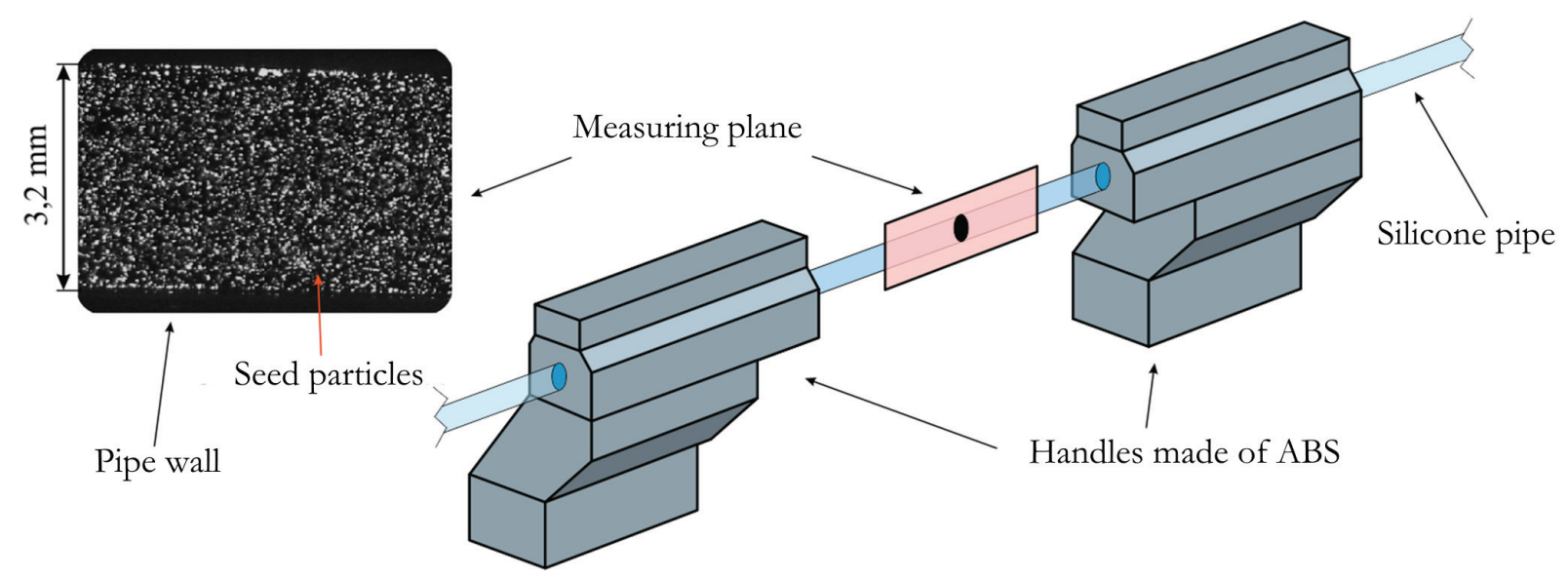

Fig. 2. Diameter measurement spot

Fig. 3. The model of the stent inside a vessel at the last step of non-linear analysis of the implementation process using the iterative numerical procedure

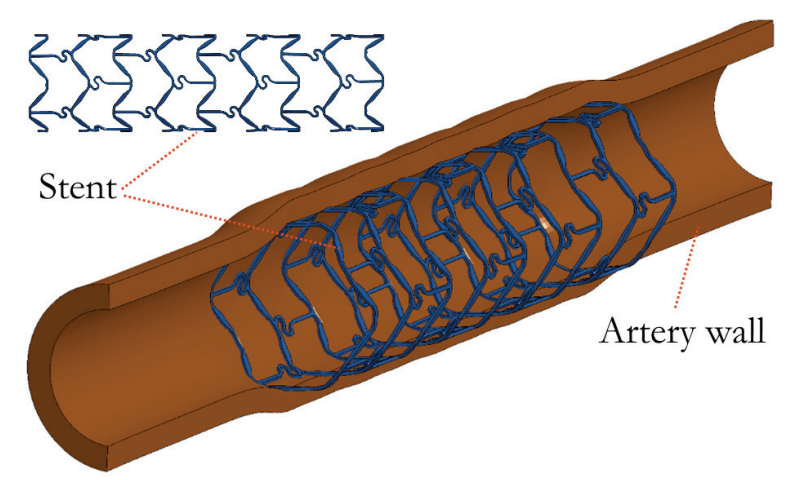




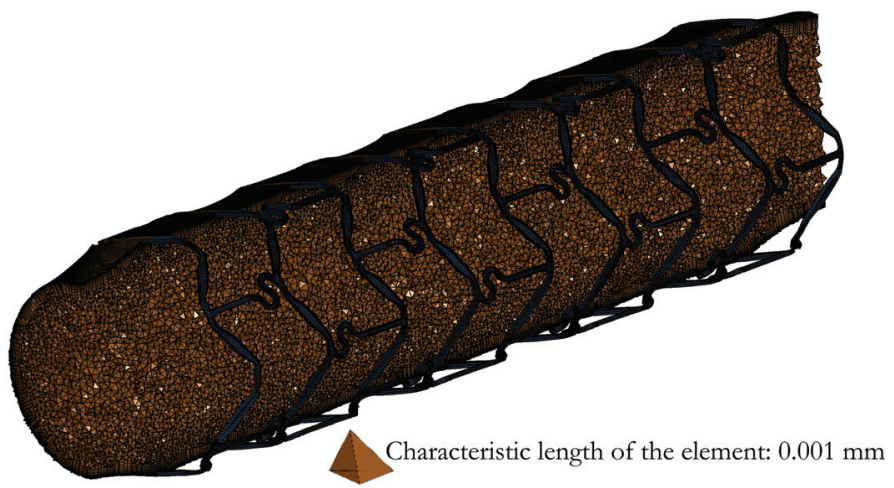

Fig. 4. Flow domain for a vessel with a stent

is a dimensionless parameter describing the distance of the first element from the wall [14].

\subsubsection{Numerical model: statistical stenosis}

Modelling of statistical stenosis was based on mapping the outlines (characteristic boundaries) of the cross-sections of the coronary vessels (Fig. 5a) taken from the results of the medical testing of pathological changes [20]. The obtained geometrical model was then discretized in order to create a numerical model consisting of 7489523 finite volumes. In the stenosis section, the mesh was densified (Fig. 5b). The atheroscle- rotic plaque for this case was continuous to smoothen out the transition between the vessel and the plaque. Table 1 presents the basic geometrical parameters of the vessel with the statistical stenosis.

\subsubsection{Numerical model: real stenosis}

While developing a geometrical model for real stenosis, the cross-sections of a sample coronary vessel were used. During the model development, three basic areas were distinguished: a vessel lumen, area of the atherosclerotic plaque growth, and an actual vessel wall. Plaque is characterized with stochastic shapes,

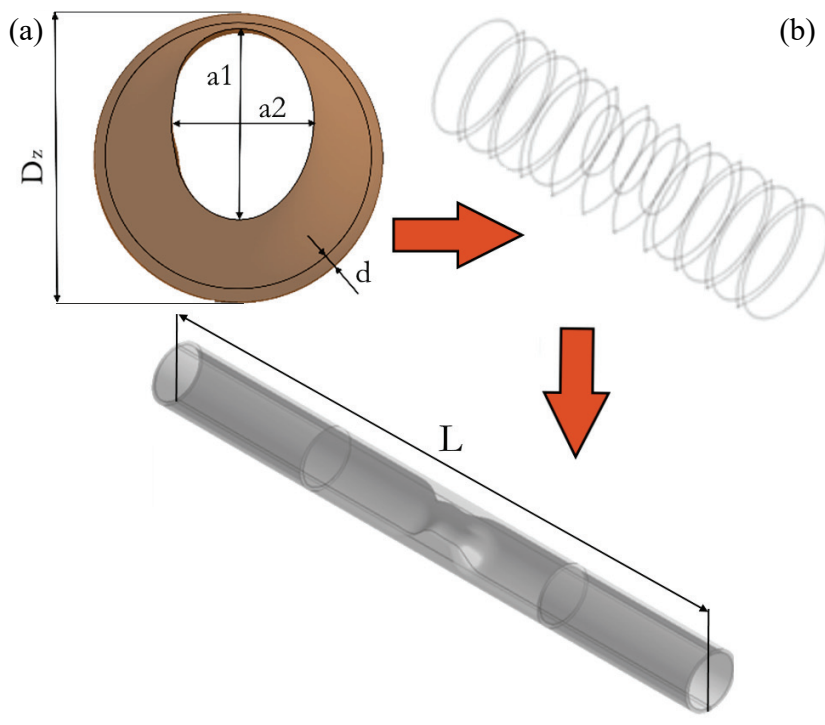

(b)

Fig. 5. Statistical stenosis: (a) geometrical model, (b) discretized flow domain

Table 1. Geometrical parameters of the vessel with statistical stenosis

\begin{tabular}{|c|c|c|c|c|c|}
\hline $\begin{array}{c}\text { Outer diameter } \\
D_{z}[\mathrm{~mm}]\end{array}$ & $\begin{array}{c}\text { Wall thickness } \\
d[\mathrm{~mm}]\end{array}$ & $\begin{array}{c}\text { Area stenosis } \\
{[\%]}\end{array}$ & $\begin{array}{c}\text { Diagonal of ellipse } \\
a_{2}[\mathrm{~mm}]\end{array}$ & $\begin{array}{c}\text { Diagonal of ellipse } \\
a_{1}[\mathrm{~mm}]\end{array}$ & $\begin{array}{c}\text { Length } \\
L[\mathrm{~mm}]\end{array}$ \\
\hline 3.4 & 0.2 & 55.0 & 1.7 & 1.6 & 60.0 \\
\hline
\end{tabular}




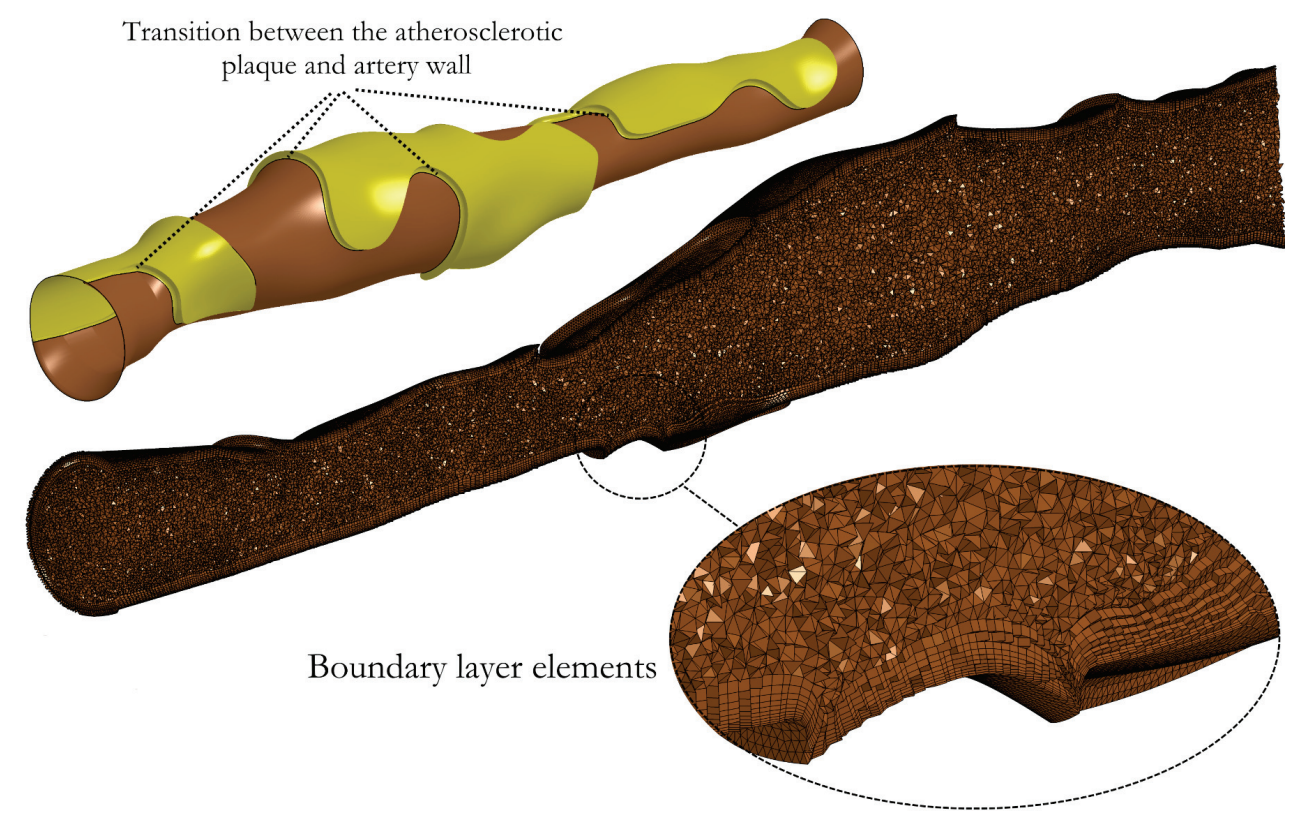

Fig. 6. Real stenosis: geometrical model and discretized flow domain

complete asymmetry and uneven cross-section thickness (Fig. 6). Apart from the plaque geometry, the geometry of the coronary vessel wall with varying thickness was also obtained. Further steps were aimed at separating three layers of the wall: the inner, central (with varied thickness) and outer membranes. To create the flow domain, the geometry needed to be modified to fill the empty space with the finite volumes. The mesh was densified, in the spots that required it, to accurately reflect the vessel curvature. The elements were generated in such a manner so as to obtain a smooth transition from the smallest elements to the bigger elements with an initially defined size. The discrete 3D model contained 8470429 finite volumes (Fig. 6).

\subsubsection{Model development of the vessel with an implemented stent}

The third case represented a vessel after angioplasty procedure (stent implantation). Taking real life conditions into consideration, to analyse the flow in vessel after angioplasty it would be necessary to perform the imaging process immediately after the angioplasty procedure, however, it was not possible due to technical issues. Therefore, it was decided to imitate the angioplasty procedure through additional numerical simulations in order to obtain the desired geometrical domain, similarly as in paper [2]. It is important to specify that the geometry used for the flow domain was obtained through a non-linear simulation of the balloon expansion inside a blood vessel using the implicit analysis method algorithms available in the LS-Dyna software. The Finite Element (FE) model is presented in Fig. 7 as a cross-section of the last step in the aforementioned simulation. The whole model contained 677112 finite elements. The FE model consisted of 3 main parts: a stent, atherosclerotic plaque and a vessel wall. Different mesh densities were used in order to accurately reflect the vessel shape. After discretization, a model containing 280258 finite elements and 139694 nodes was obtained. The model was filled out with the elements, and areas of expected disturbances had specifically denser mesh. As a result of the volume discretization, a model containing 7095156 finite volume elements was obtained (Fig. 8).

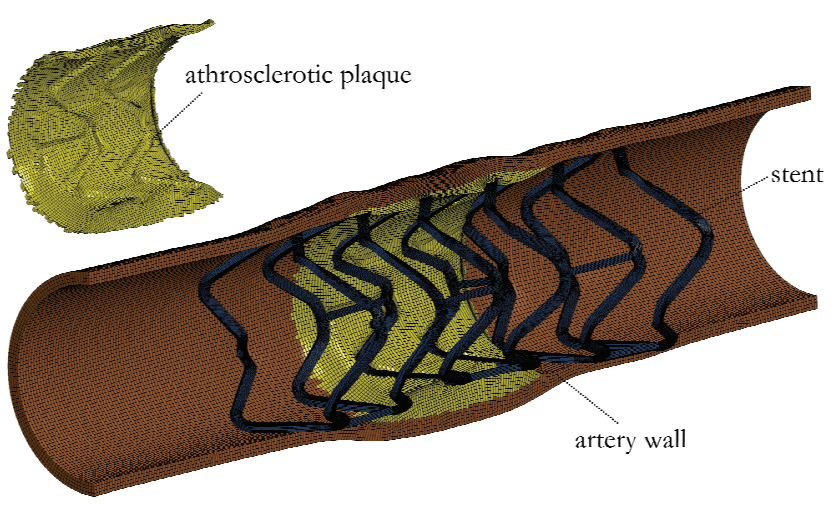

Fig. 7. FE numerical model of coupling of the stent with the vessel after the angioplasty process 


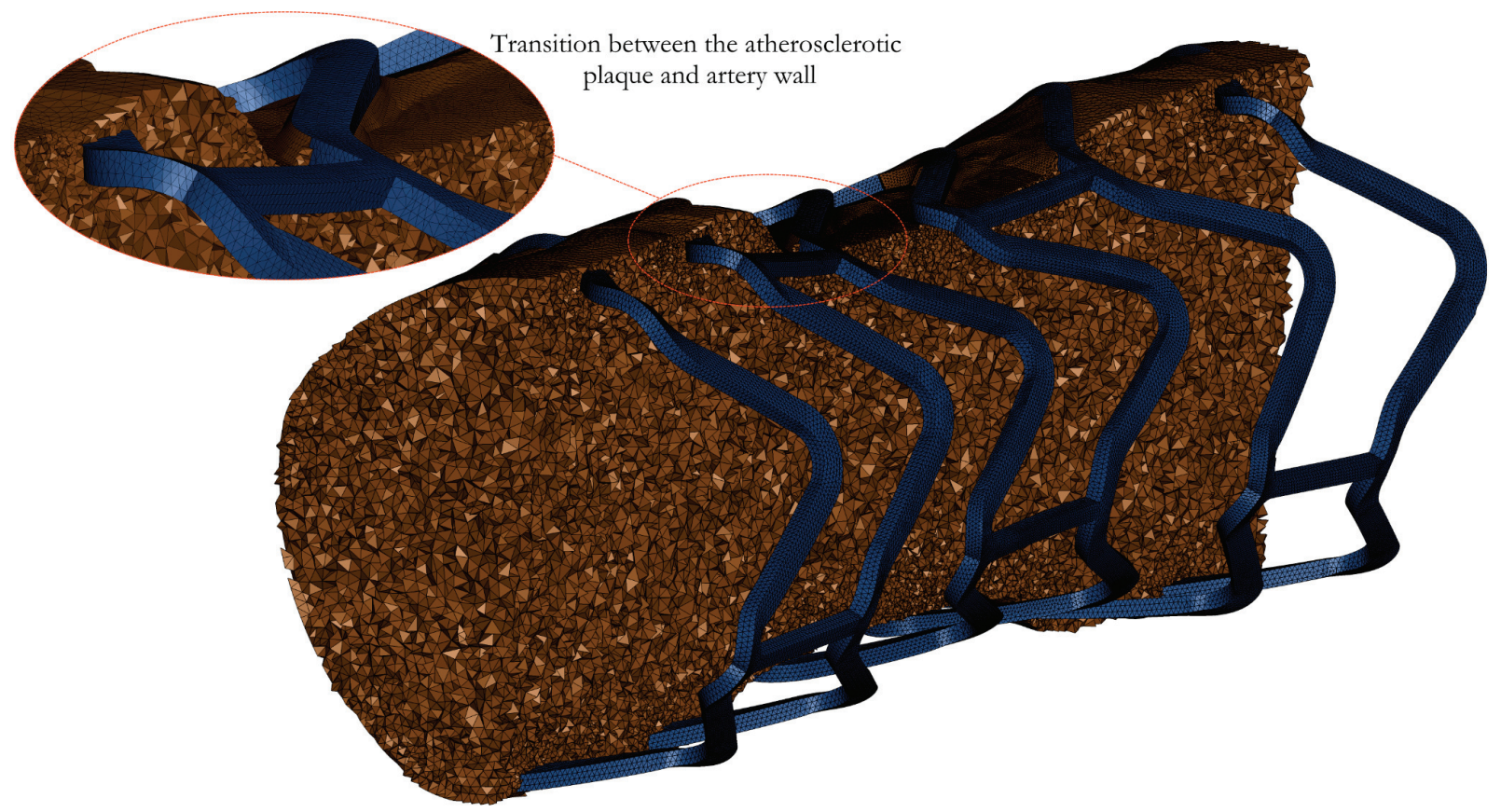

Fig. 8. Discretized flow domain model - a cross-section view

\subsubsection{Initial and boundary conditions}

In order to perform the flow analysis, initial boundary conditions needed to be set. For blood flowing in a vessel, it was necessary to set the following initial conditions: inlet velocity (Fig. 9a), outlet pressure (Fig. 9b) and viscosity definition as a function of shear stress [6], [23]. In a real life flow, the pressure does not have a constant value. An average systole pressure is around $16.0 \mathrm{kPa}(120 \mathrm{mmHg})$, while the diastole pressure is around $10.7 \mathrm{kPa}(80 \mathrm{mmHg})$. A variable in time pressure value was applied to the surface defining the outlet as a "pressure-outlet" condition. A velocity value is representing the pulsating nature of the heartbeat. The velocity was defined as a periodic function by implementing the UDF (User De- fined Function). In the case of the vessels with the atherosclerotic lesions, sudden changes in the crosssection can occur, causing the reduction of the vessel lumen. In such areas, the blood flow becomes turbulent. As the blood is a non-Newtonian fluid, it was defined with the Carreau model in which viscosity is related to shear velocity and shear stress [6], [24]. For the cases based on the curves taken from literature [7], the curves used at the inlet and at the outlet are presented in Fig. 9. For the cases imitating the experimental cases, the curves registered by the sensors used during the measurements were applied. Exemplary experimental curves for the case with $30 \mathrm{rpm}$ and pressure of $16.7 / 11.3 \mathrm{kPa}$ $(125 / 85 \mathrm{mmHg})$ are presented in Fig. 10. In the study, it was decided to perform an initial analysis using a straight tube as it was presented in the authors' previous work [21].
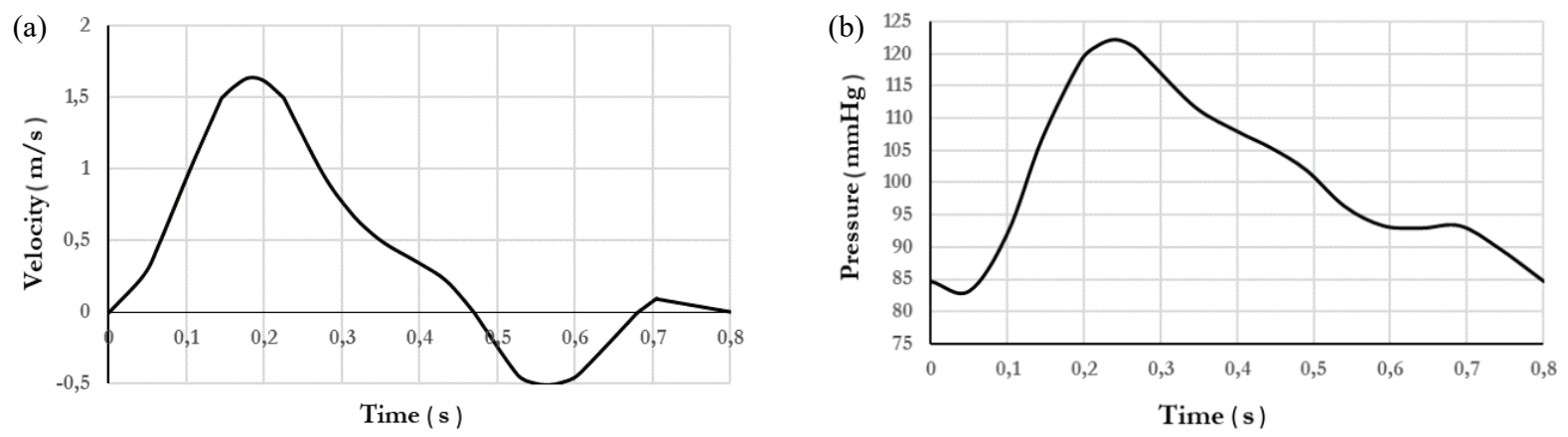

Fig. 9. Curves used in analyses: (a) inlet velocity curve, (b) outlet pressure curve 


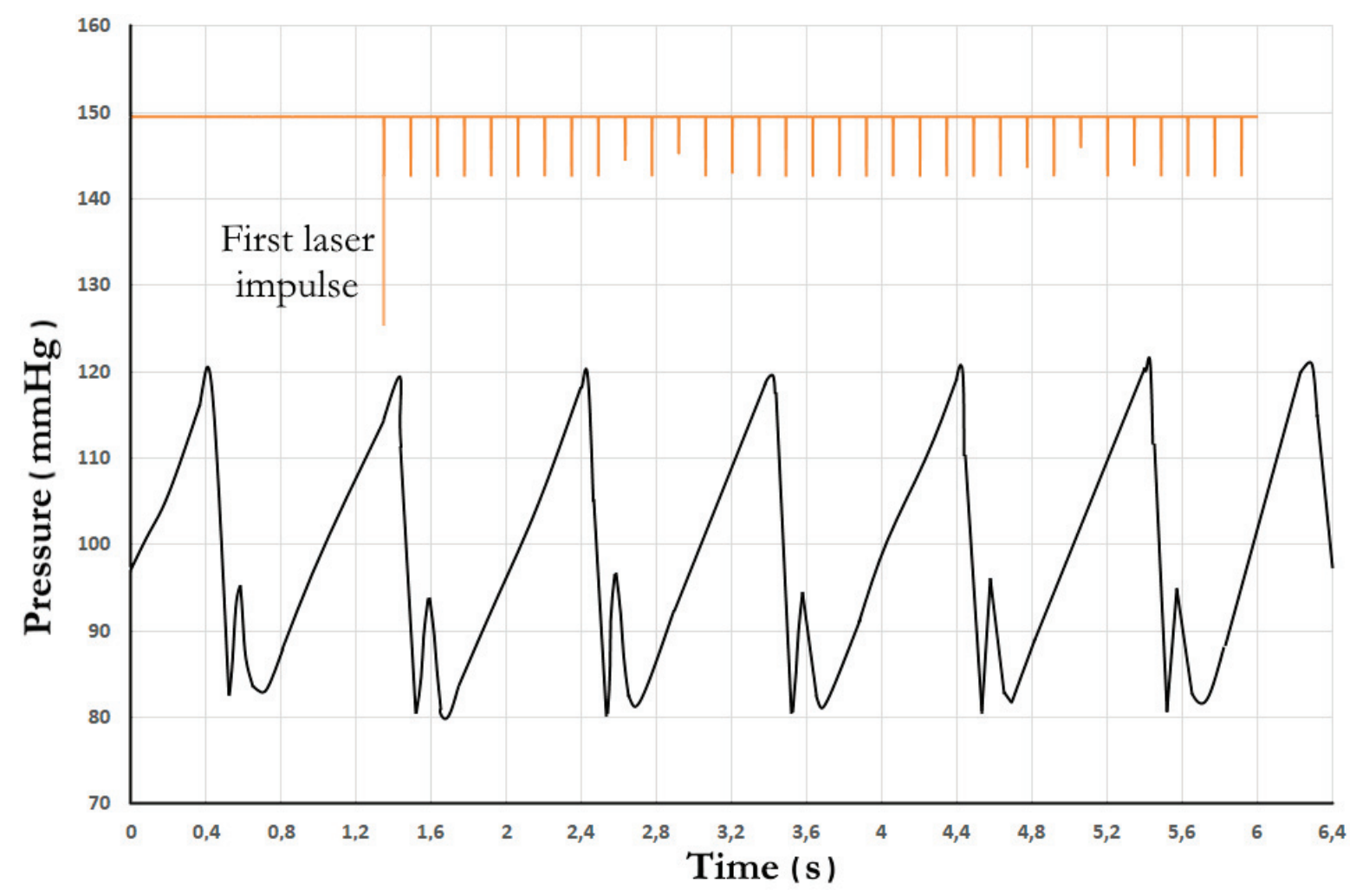

Fig. 10. Exemplary pressure characteristic as a function of time for the inlet experimental curve for the case with $30 \mathrm{rpm}$ and pressure of $16.7 / 11.3 \mathrm{kPa}(125 / 85 \mathrm{mmHg})$

\section{Results}

\subsection{Experimental results}

Using the PIV method, velocity vector distribution results were obtained during the tests for 2 different pump settings. The velocity vector distribution was evaluated for two recorded areas. Post-processing of the results consisted in stitching 4 or 3 measurements together. For the measurement in which the recorded area was observed at a higher magnification, four separate PIV measurements had to be made and were then combined together during the post-processing procedure. When the measurements were made at lower magnification, the velocity map of the entire stent area could be obtained with only three measurements. The case with a stent with the external diameter greater than the internal diameter of the tube was analysed. While testing the system, the following parameters were achieved:

- case 1 - pressure on the output was $16.7 / 11.3 \mathrm{kPa}$ $\left(125 / 85 \mathrm{mmHg}\right.$ ) and the flow was $0.47 \mathrm{dm}^{3} / \mathrm{min}$, which corresponds to frequency of heart operation equal to $1 \mathrm{~Hz}(30 \mathrm{rpm}$ for peristaltic pump) and the normal arterial pressure

- case 2 - pressure on the output was $22.3 / 16.0$ $(167 / 120 \mathrm{mmHg})$ and the flow was $0.83 \mathrm{dm}^{3} / \mathrm{min}$, which corresponds to frequency of heart operation equal to $1 \mathrm{~Hz}$ and mild hypertension

The stent structure consisting of numerous strengthening struts hinders the flow registration process. The method for measuring the velocity distribution is exactly described in [17]. The stent used in these analyses was $0.125 \mathrm{~mm}$ thick and the percentage of area filling in relation to the full tube area was $18.3 \%$. This data is shown in the stent code description: stent B $-0.125 / 18.3$. In Figure 11, the distribution of the velocity vectors for the case with $30 \mathrm{rpm}$ and pressure of $16.7 / 11.3 \mathrm{kPa}(125 / 85 \mathrm{mmHg})$ for two analysed expositions is presented. For the singular exposition, the measurement was carried out during a single cycle, while the results were processed by dividing the analysed section into three sub-sections. As can be seen on the maps shown, a singular exposition exhibits an increase in velocity, which may result from changes of the pump work characteristic. This increase is not significant and does not exceed $0.1 \mathrm{~m} / \mathrm{s}$. The results for the second pump operation parameters are shown in Fig. 12. 


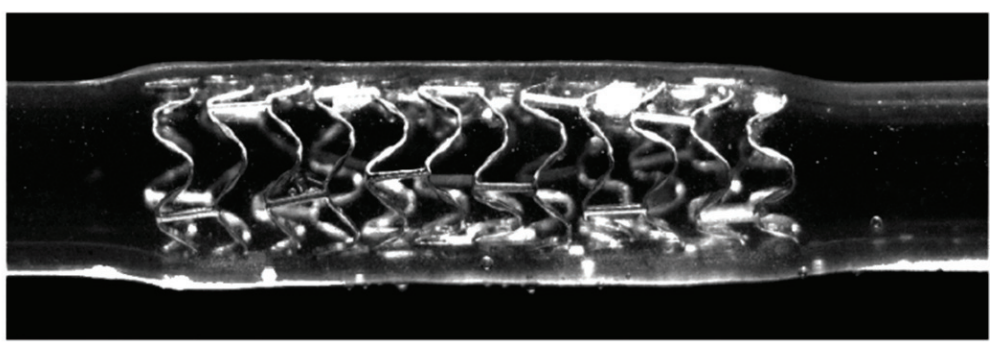

Flow direction
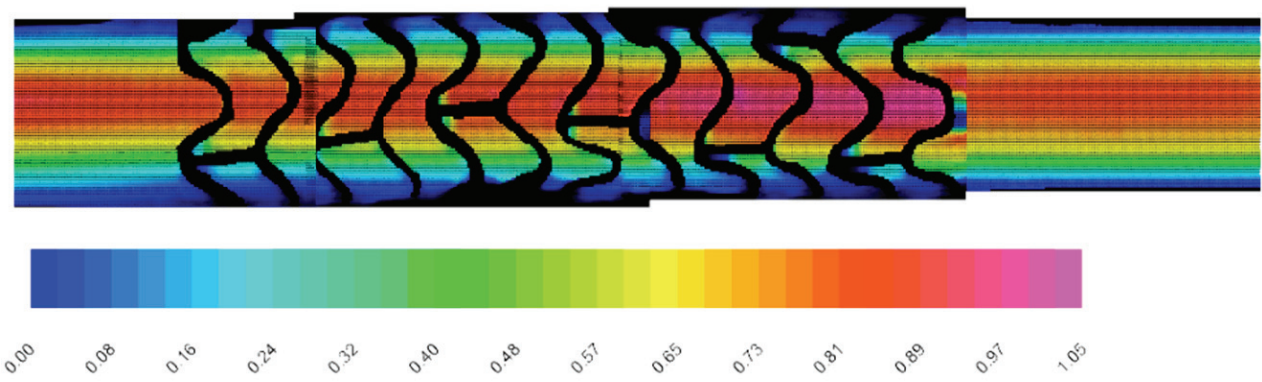

$\left[\mathrm{m} / \mathrm{s}^{\wedge}-1\right]$
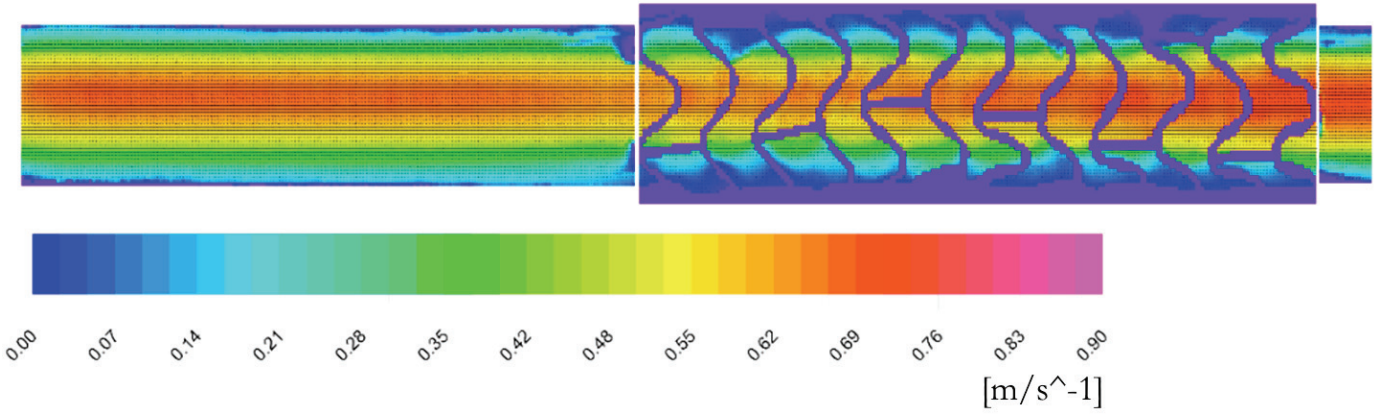

Fig. 11. Comparison of an averaged distribution of velocity vectors for two recorded areas - the case with $30 \mathrm{rpm}$ and pressure of $16.7 / 11.3 \mathrm{kPa}(125 / 85 \mathrm{mmHg})$
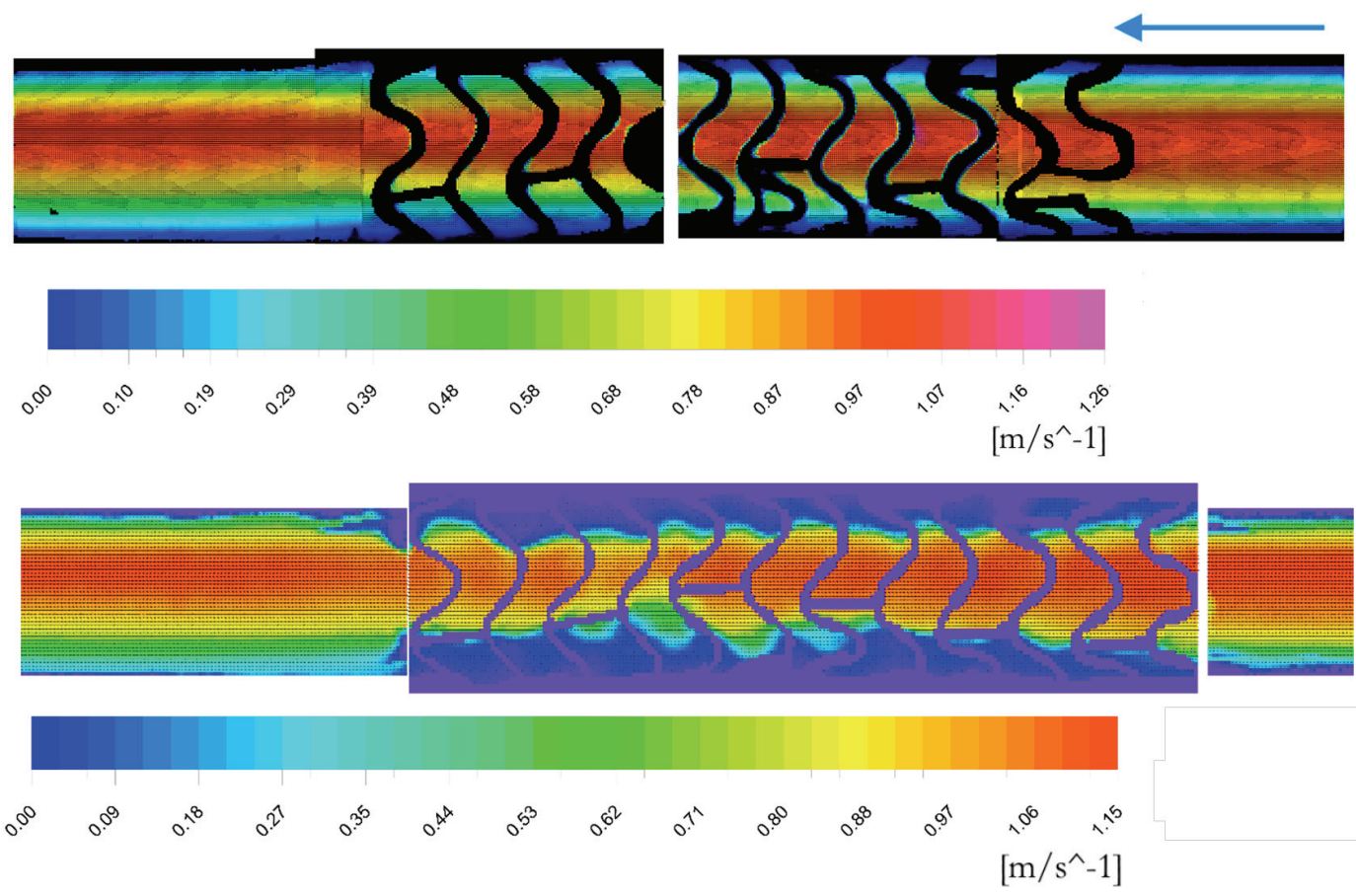

Fig. 12. Comparison of an averaged distribution of velocity vectors for two recorded areas - the case with $30 \mathrm{rpm}$ and pressure of 22.3/16.0 $\mathrm{kPa}(167 / 120 \mathrm{mmHg})$ 


\subsection{Comparison of the experiment results with the numerical simulation}

For the comparison reasons, the case in which frequency of heart operation was equal to $1 \mathrm{~Hz}$ and had the pressure of $22.3 / 16.0 \mathrm{kPa}(167 / 120 \mathrm{mmHg})$ was selected. Based on the distribution of averaged velocity vectors, the highest registered flow velocity values (around $1.03 \mathrm{~m} / \mathrm{s}$ for the experimental test and $1.15 \mathrm{~m} / \mathrm{s}$ for the numerical simulation) were recorded at the inlet of the vessel (Fig. 13). This effect is present both in the experimental tests and the numerical simulations. After reaching the above-mentioned values, the velocity vectors decrease towards the outlet of the stented area,

(a)

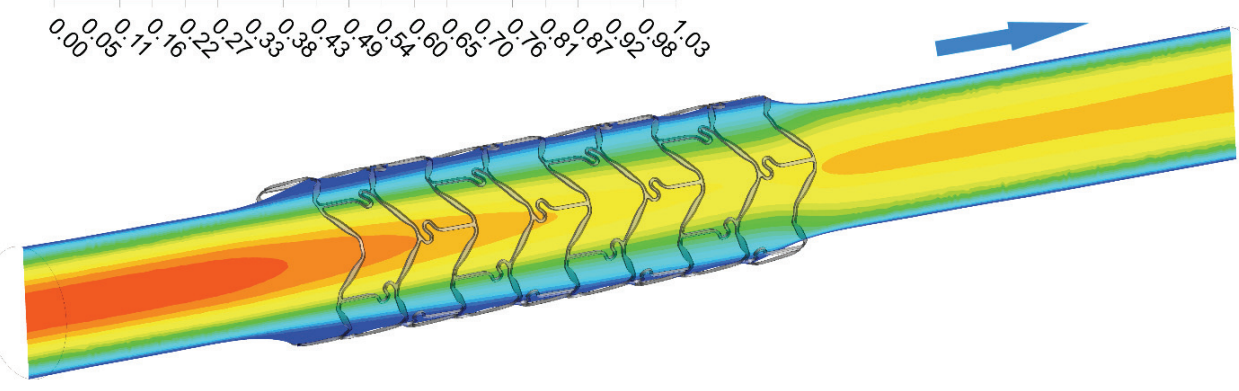

(b)

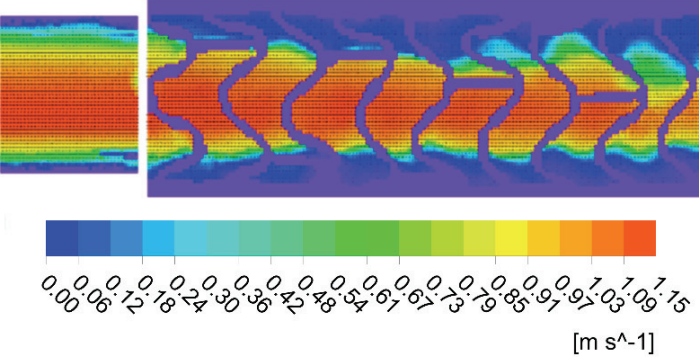

Fig. 13. Comparison of velocity vectors averaged in time for the case with $30 \mathrm{rpm}$ and pressure of 22.3/16.0 $\mathrm{kPa}(167 / 120 \mathrm{mmHg})$ : a) numerical analysis, b) experimental analysis

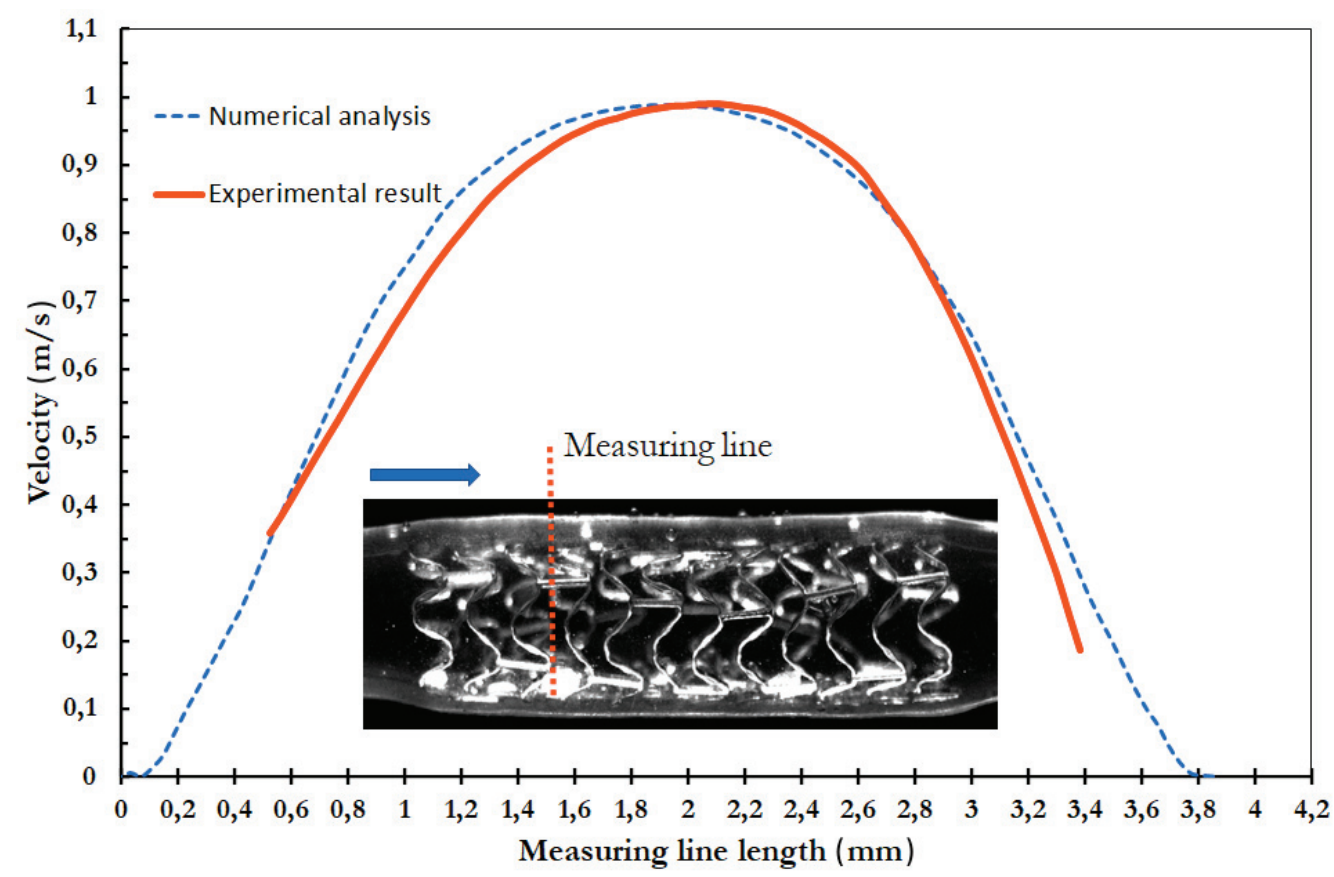

Fig. 14. Comparison of velocity profiles for the vessel with a stent obtained through both a numerical simulation and an experiment $30 \mathrm{rpm}$ and pressure of $22.3 / 16.0 \mathrm{kPa}(167 / 120 \mathrm{mmHg})$ 
and then increase in the end of the artery. This effect is closely related to the enlargement of the diameter in the middle part of the vessel caused by expansion of the balloon during the stent implementation process. Such a situation frequently appears when a stent is postdilateted or a balloon in the angioplasty process is over pressured.

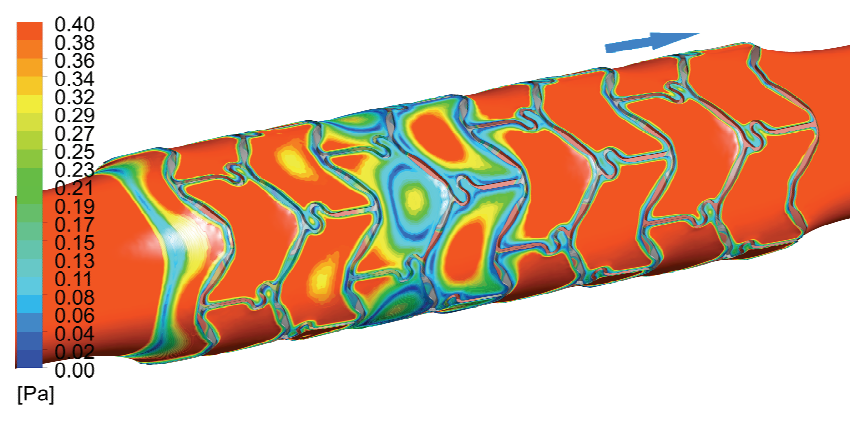

Fig. 15. Distribution of averaged shear stress (TAWSS); values from 0.0 to $0.4 \mathrm{~Pa}$

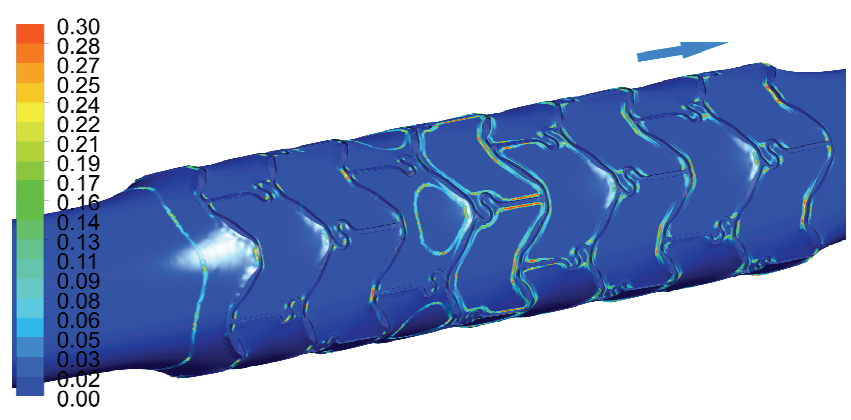

Fig. 16. OSI index map; values from 0.0 to 0.3

In Figure 14, distributions of the average velocity profiles obtained on the basis of both the experimental tests and the numerical simulations are presented. It can be observed that the numerical results are close to the experimental outcomes, i.e., both the velocity distribution and its values are almost similar. The main difference is visible near the vessel wall due to adhesion of the seeding particles near the stent struts during the experimental testing. This adhesion leads to smudged spots near the wall. This phenomenon makes it difficult or even impossible to measure velocity vectors near the walls, which can be seen in Fig. 16.

Based on the shear stress values averaged (TAWSS) versus time, it is clearly visible that the areas with unfavourably low shear stress values (below 0.4 Pa) are located at the inlet of the vessel and around the stent struts (Fig. 15). The areas of low shear stress are located in the stagnation zone visible on the velocity vector map. The balloon geometry resulted in stent asymmetrical position and caused it to be adjacent to the vessel more on one side than on the other, which then caused an uneven stagnation zone distribution. High OSI parameter values, around 0.3 , are located close to the stent struts (Fig. 16).

\subsection{Numerical cases - analysis results}

From the performed simulations, the distributions of velocity for each domain were obtained. The flow analysis was performed using the coupling method with the turbulence model $k-\omega \mathrm{SST}$. The integration time step was $0.004 \mathrm{~s}$ (200 steps required for calculating one full heartbeat cycle lasting $0.8 \mathrm{~s}$ ). For each case, the distributions of time average wall shear stress (TAWSS), oscillatory shear index (OSI). Distribution of values of the velocity vectors was presented for the moment in which the flow velocity was the highest $-0.19 \mathrm{~s}$.

\subsubsection{Statistical stenosis case}

The velocity vector value distribution provides information how the fluid stream behaves after passing the modelled stenosis. As shown in Fig. 17, the narrowing induces a local change in the flow velocity. The maximal velocity registered during the analysis reached the value of $6.61 \mathrm{~m} / \mathrm{s}$. The stream, after passing through the stenosis, flows closer to one side, making it asymmetric. The distribution of the velocity vector values shows that there is a turbulence region, located behind the stenosis, in which the velocity values are low, i.e., close to $0.0 \mathrm{~m} / \mathrm{s}$. The TAWSS and OSI are important for the flow analysis. The distribution of shear stress averaged in time (Fig. 18a) shows that areas with an increased risk of atherosclerosis developing are concentrated near the narrowing and at the end of the blood stagnation zone, which is then confirmed through analysis of the OSI distribution (Fig. 18b).

\subsubsection{Real case with stenosis}

Based on the flow velocity vectors (Fig. 19) for the contraction phase of the heartbeat, it is noticeable that the highest velocity is reached by the streams situated close to the axis of the vessel. In the section with the greatest stenosis of the vessel lumen, the velocity values reach $3.58 \mathrm{~m} / \mathrm{s}$ during the heart contraction phase. It is visible that for the vessel with a stenosis that varies in size along its length, the stream is much more varied when compared to the vessel with a singular stenosis. The distribution of 


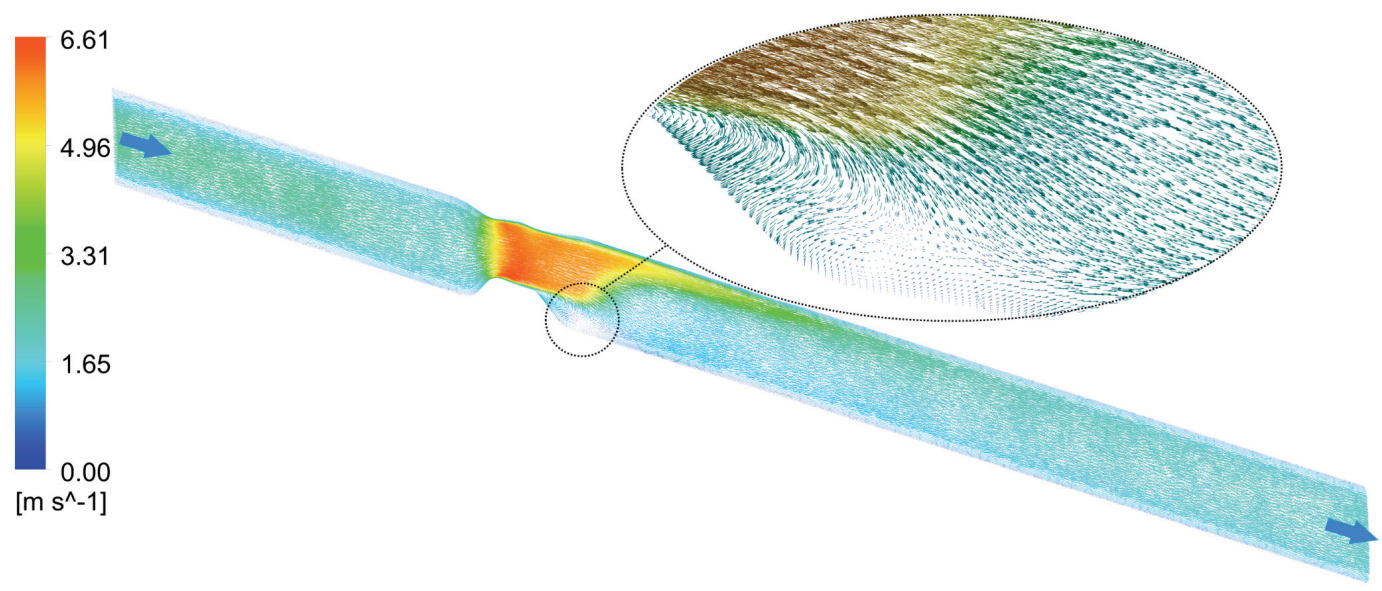

Fig. 17. Velocity vectors distribution of $0.19 \mathrm{~s}$ phase $\mathrm{m} / \mathrm{s}$

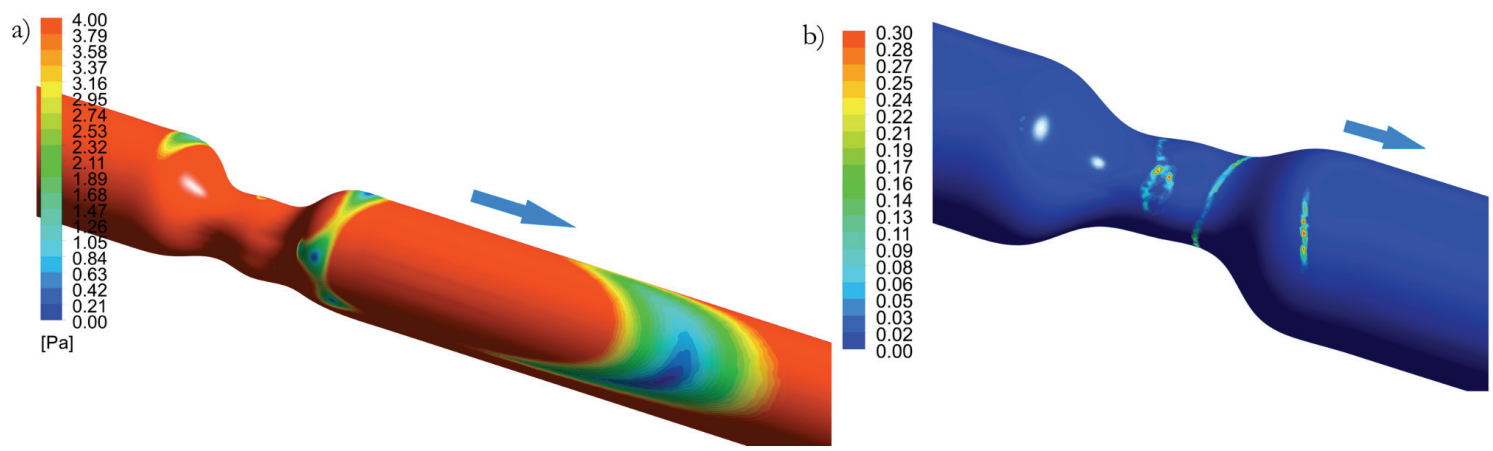

Fig. 18. Distribution of: a) shear stress averaged in time (TAWSS) for values from 0.0 to $0.4 \mathrm{~Pa}$, b) OSI index map; values from 0.0 to 0.3

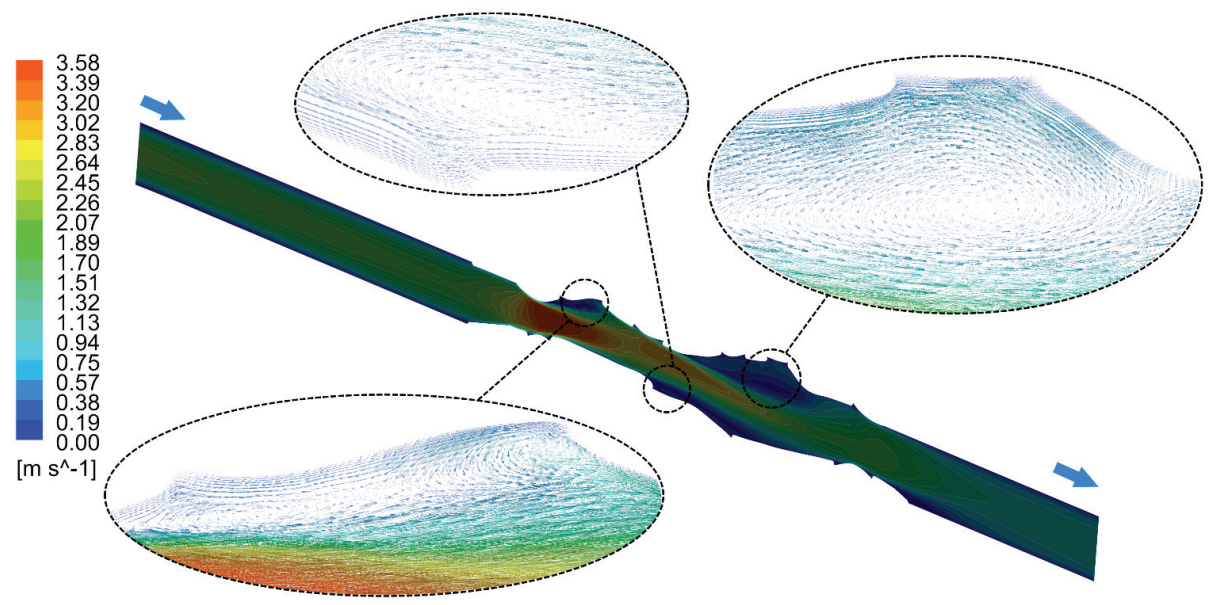

Fig. 19. Velocity vectors distribution of $0.19 \mathrm{~s}$ phase for real stenosis $\mathrm{m} / \mathrm{s}$

values of velocity vectors, shown in Fig. 19, shows how many areas of turbulences appear for this type of geometry. In these areas, the substances responsible for development of the atherosclerotic tissue concentrate. It also visible that behind the stenosis numerous areas of low velocities appear. Those areas are in places where the atherosclerotic plaque can appear. The areas where the shear stress values are lower are especially susceptible to vascular diseases.
While analysing the TAWSS values of the vessel with a real stenosis, it can be clearly observed that areas with dangerously low shear stress values are located close to the transitions between the atherosclerotic plaque and the healthy tissue as well as in the blood stagnation zones. (Fig. 20). Shear stress values with oscillating character can be observed at the transition between the atherosclerotic plaque and the healthy tissue (Fig. 21). 


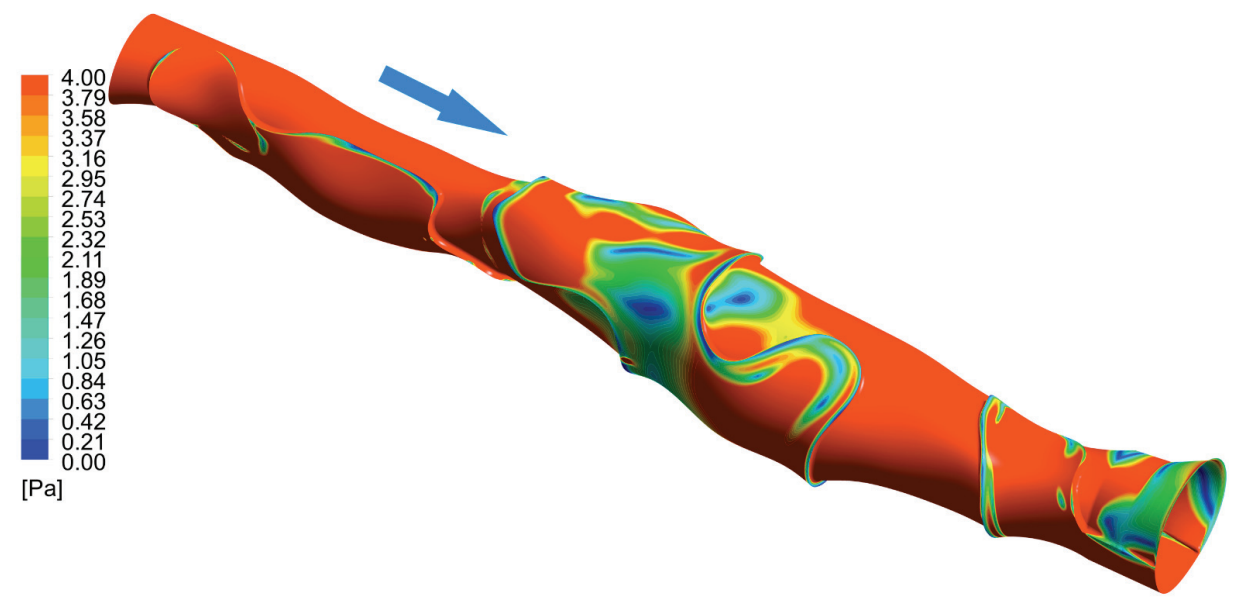

Fig. 20. Distribution of shear stress averaged in time (TAWSS) for values from 0.0 to $0.4 \mathrm{~Pa}$

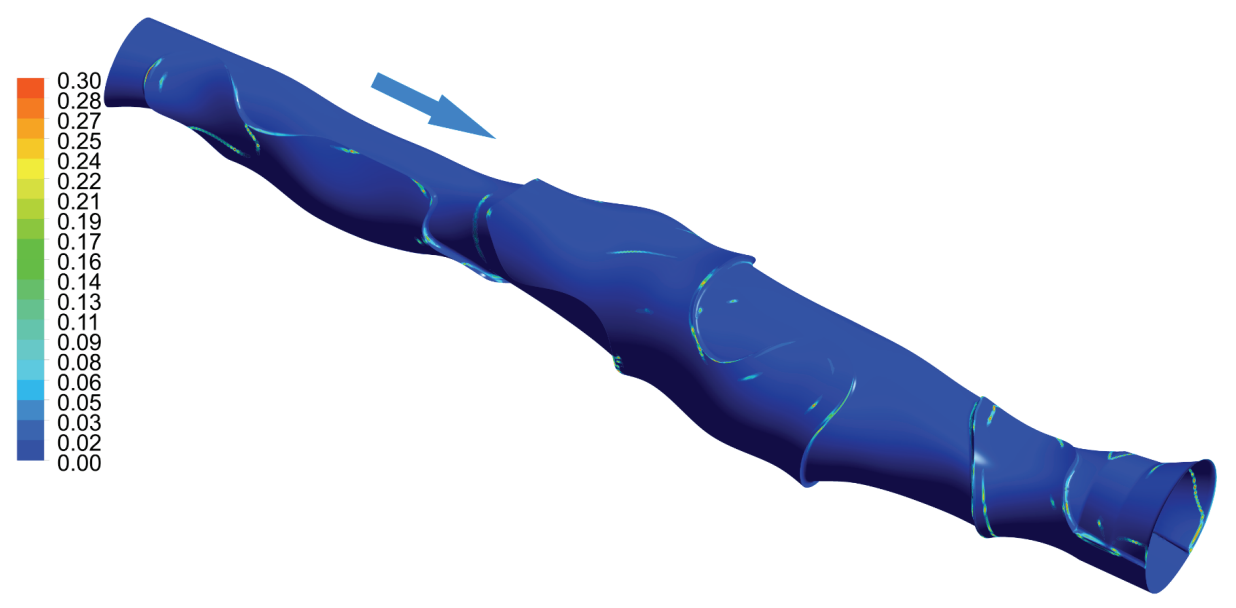

Fig. 21. OSI index map for real stenosis; values from 0.0 to 0.3

\subsubsection{Vessel after performed angioplasty}

The case of the vessel after angioplasty procedure was performed in order to show how the stent influences the flow characteristic. The velocity distribution in the vessel, in which the angioplasty procedure was performed, is presented in Fig. 22. It can be noticed that stent implementation dramatically improves the flow distribution. The area where the flow disorders occur is significantly reduced. The maximal velocity decreased from $6.61 \mathrm{~m} / \mathrm{s}$ in the stenosis vessel to 3.12 $\mathrm{m} / \mathrm{s}$ in the vessel with the stent called "treated vessel".

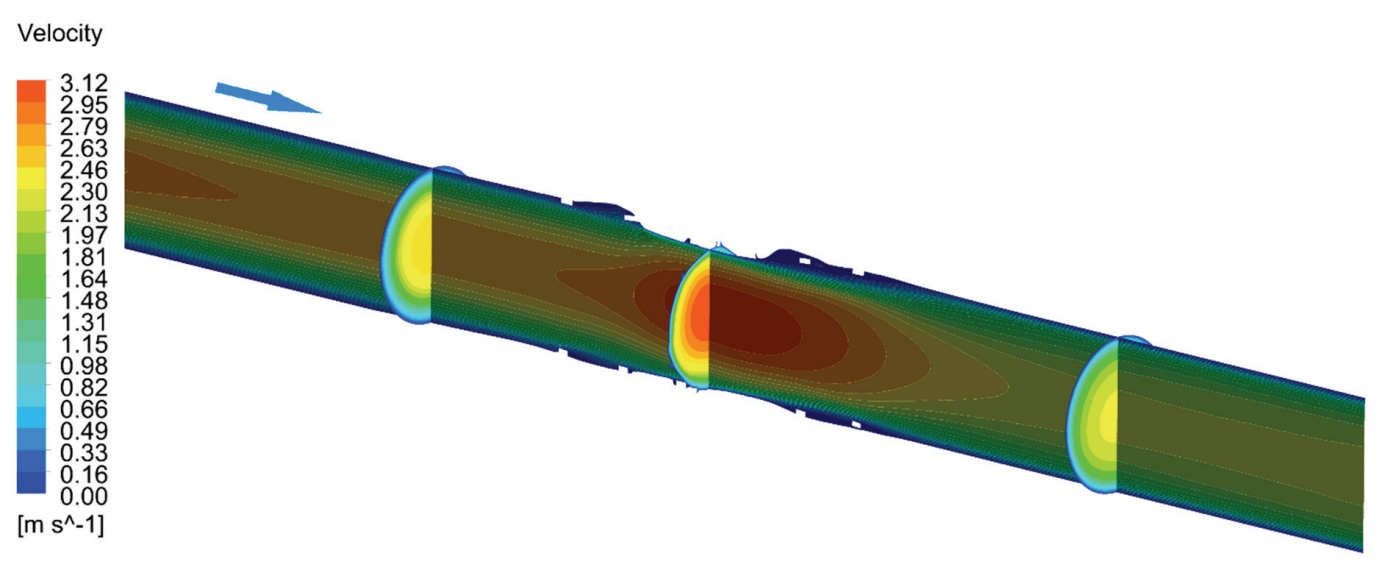

Fig. 22. Velocity vector distribution for the vessel with the implanted stent 

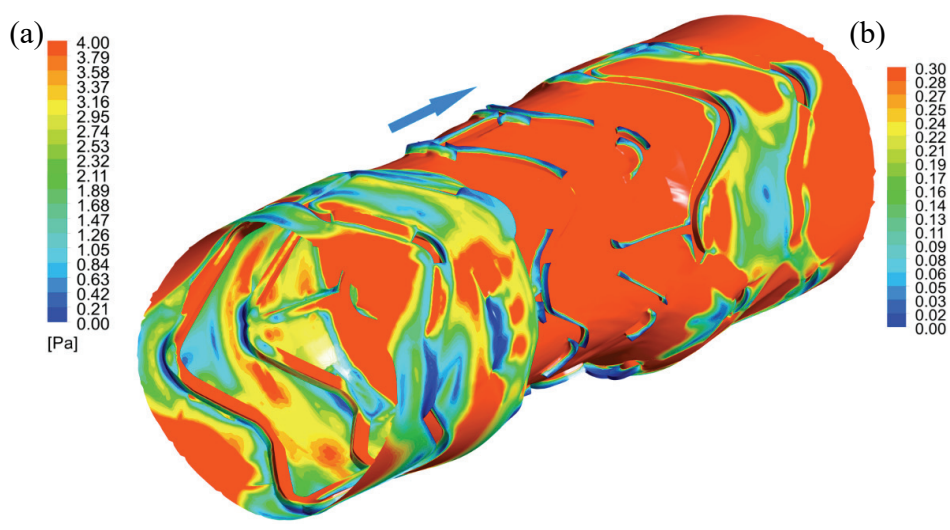

Fig. 23. Numerical result for vessel after performed angioplasty:

a) Distribution of the averaged shear stress (TAWSS) for values from 0.0 to $0.4 \mathrm{~Pa}$,

b) OSI index map; values from 0.0 to 0.3

The transition between the stent and the atherosclerotic plaque was modelled in such a manner as to reflect grooves at places where the stent is in contact with either the plaque or the vessel. As the struts of the stent can be obstacles to the flow, they cause disturbances of the flow possible to be observed on the distribution of the averaged shear stress (Fig. 23a). In the areas where the stent contact with the vessel, a significant drop in shear stress can be observed and reaches $0.21 \mathrm{~Pa}$ value.

The oscillating character of this stress is confirmed by the OSI distribution. Areas that are at risk of atherosclerotic plaque formation are the places where the stent knees meet the vessel walls (Fig. 23b).

\section{Discussion}

The goal of the paper was to present a numerical simulation of a blood flow in various types of vessels, using the computational fluid dynamics and validation of the presented modelling method with the use an original research test stand designed for studying the fluid flow. The paper presents a method that allows for analysing different types of vessel geometries. The original research test stand was developed during the study, which enabled the authors to test the flow with different pump operation parameters. Additionally, after minor modifications, various types of vessels, i.e., with a stenosis or with bifurcation, can be investigated. The use of the peristaltic pump allows controlling the pumping frequency in a fluid set volume which can be changed by modifying the pipe diameter.

The results of the study presented in the paper confirmed the data available in the literature, namely that low values of shear stress $(<0.5 \mathrm{~Pa})$ are concentrated in close proximity of stent struts [4]. Such information concerning the stresses is important from a medical point of view, as it allows assessing the areas at risk of stent restenosis. When designing a stent, it is possible to assess an impact of the stent geometry and the flow conditions on the stress distribution. At the same time, it is possible to analyse the pressure distribution in front of and behind the measuring segment. Application of the suitable lenses enabled obtainment of better imaging of the velocity vectors in the area around the stent struts. A difference in method concerned combining several images, taken at greater magnification, into a single one, allowing for a better accuracy, while reflecting the flow character. This is also one of the elements considered by the Authors to be their original achievement allowing for more accurate and reliable results.

In addition, in the study, the models and analyses for vessel geometries, such as a vessel with a stenosis, statistical stenosis, and a statistical stenosis with a atherosclerotic plaque after angioplasty procedure, were created and tested. The most important hemodynamic parameters, which the authors were able to assess, were WSS, TAWSS, OSI. Assessing the distribution of those parameters allows for pin-pointing of areas with an increased risk of restenosis development.

The measurement flow was performed for two different pressure characteristics reflecting the heartbeat. Then, for the chosen case, a numerical study was conducted using the initial boundary conditions based on the curves obtained from the experimental tests. The case was then validated, and the results correlation was deemed acceptable. In the vessel in which the angioplasty procedure was performed, the areas with an atherosclerotic plaque low shear stress values distribution are between the stent struts. The flow analysis for the real stenosis (Fig. 19) and the statistical 
stenosis (Fig. 17) depicted that the areas at risk of the atherosclerotic plaque growth are concentrated near the cross-section narrowing. For the case with the statistical stenosis, an area containing characteristic flow disturbances appeared after passing the narrowed section.

The stent geometry significantly influences the results obtained from the PIV test method. Using the sharpening technique on the seeding particles allows visualizing the whole flow. During the numerical analysis, the stent was expanded by a balloon causing axial positioning in the vessel. It is important to note that the resulting stent deformation during the simulation was not symmetrical, which caused some parts of the stent to be adhered more to the vessel than others. This influenced the shear stress distribution, in which the areas with low values were concentrated in the inlet part and around the stent struts. Each arch causes flow disturbances. In spots with those disturbances, the areas with low velocity values, called the "stagnation zones", appear. This leads to build-up of the unused products in the atherosclerotic plaque accretion.

\section{Conclusions}

Using numerical methods allows not only for analysing the flow characteristics, but also indicating the areas of low and oscillating shear stresses, which may impede upon results of coronary angioplasty. As the tests of the case with a stent shows, the areas of low TAWSS values are concentrated close to the stent struts. This can have important implications on stent design. Flow disturbances caused by the stent struts can be minimized by reducing its thickness and using more streamlined shapes of the struts. For the stent whose external diameter is greater than the internal diameter of the vessel, the shear stress distribution is different. Stents with increased diameters, compared to the normal vessel diameter, create a higher risk of occurrence of the areas with low WSS values. Excessive stent deformation can cause inflammation by injuring the vessel and can initiate the restenosis and thrombotic phenomena through the increased vessel diameter, which leads to reduction of the flow intensity and lower the TAWSS values. A greater diameter of the section with a stent can lead to occurrence of regions of a lower flow velocity along the whole stent, wherein the width of this region is greater for the inlet part.

The presented method is to be further developed by the authors to enable micro-scale analyses in order to research the flow nature and visualise the micro local turbulences responsible for the possibility of the restenosis occurrence around the stent struts.

\section{Acknowledgements}

The study was supported by the NCBiR within project APOLLO-STRATEGMED (2/269760/1/NCBR/2015). This research was performed with the support of the Interdisciplinary Centre for Mathematical and Computational Modelling (ICM) University of Warsaw under grant no. GA73-30. The authors would like to thank Mr. Arkadiusz Antonowicz for support and assistance with experimental tests.

\section{References}

[1] Beier S., Ormiston J., Webster M., Cater J., Norris S., Medrano-Gracia P., Young A., Cowan B., Hemodynamics in Idealized Stented Coronary Arteries: Important Stent Design Considerations, Ann. Biomed. Eng., 2016, 44, 315-329, DOI: 10.1007/s10439-015-1387-3.

[2] BukaŁa J., Kwiatkowski P., MaŁachowski J., Numerical analysis of crimping and inflation process of balloon-expandable coronary stent using implicit solution, Int. J. Numer. Method. Biomed. Eng., 2017, 33(12), DOI: 10.1002/cnm.2890.

[3] Bukala J., KwiatKowski P., MaŁachowski J., Numerical analysis of stent expansion process in coronary artery stenosis with the use of non-compliant balloon, Biocybern. Biomed. Eng., 2016, 36, 145-156, DOI: 10.1016/j.bbe.2015.10.009.

[4] Chen Y., Xiong Y., Jiang W., Yan F., Guo M., Wang Q., FAN Y., Numerical simulation on the effects of drug eluting stents at different Reynolds numbers on hemodynamic and drug concentration distribution, Biomed. Eng. Online, 2015, 14, DOI: 10.1186/1475-925X-14-S1-S16.

[5] Chiastra C., Morlacchi S., Gallo D., Morbiducci U., Cardenes R., Larrabide I., Migliavacca F., Computational fluid dynamic simulations of image-based stented coronary bifurcation models, J. R. Soc. Interface, 2013, 10, DOI: 10.1098/rsif.2013.0193.

[6] ChO Y.I., KenSEY K.R., Effects of the non-Newtonian viscosity of blood on flows in a diseased arterial vessel. Part 1: Steady flows, Biorheology, 1991, 28, 241-262, DOI: 10.3233/ BIR-1991-283-415.

[7] JóźwIK K., OBIDOwsKi D., Numerical simulations of the blood flow through vertebral arteries, J. Biomech., 2010, 43, 177-185, DOI: 10.1016/j.jbiomech.2009.09.026.

[8] KoperniK M., TOKARCZYK P., Development of multi-phase models of blood flow for medium-sized vessels with stenosis, Acta Bioeng. Biomech., 2019, 21 (2), 63-70.

[9] Koskinas K.C., Chatzizisis Y.S., Antoniadis A.P., GianNoglou G.D., Role of Endothelial Shear Stress in Stent Restenosis and Thrombosis: Pathophysiologic Mechanisms and Implications for Clinical Translation, J. Am. Coll. Cardiol, 2012, 59, 1337-1349, DOI: 10.1016/J.JACC.2011.10.903.

[10] Kozuń M., PŁoneK T., Jasiński M., Filipiak J., Effect of dissection on the mechanical properties of human ascending aorta and human ascending aorta aneurysm, Acta Bioeng. Biomech., 2019, 21 (2), 127-134.

[11] KWIATKOWSKI P.S., MAŁACHOWSKI J., JAKUBAS-KwiATKowsKa W., GolęBIEWSKi S., GIL R.J., KWASIBORSKi P., 
KaŁUŻA B., SutKowsKa E., The effects of types of guidewires and pressure applied during stent implantation in the main vessel on the incidence of damage to coronary guidewires during angioplasty of coronary bifurcation lesions - Wide Beast study, J. Interv. Cardiol., 2018, 31, 599-607, DOI: 10.1111/joic. 12523 .

[12] LaDisa J.F., Olson L.E., Molthen R.C., Hettrick D.A., Pratt P.F., Hardel M.D., Kersten J.R., Warltier D.C., PAGEL P.S., Alterations in wall shear stress predict sites of neointimal hyperplasia after stent implantation in rabbit iliac arteries, Am. J. Physiol. Circ. Physiol., 2005, DOI: 10.1152/ ajpheart.01107.2004.

[13] LANTZ J., RenNer J., KARlsson M., Wall shear stress in a subject specific human aorta-Influence of fluid-structure interaction, Int. J. Appl. Mech., 2011, 4, 759-778, DOI: 10.1142/S1758825111001226.

[14] Lesieur M., Fluid Mechanics and its Applications: Turbulence in fluids, 4th ed., Springer, 2008.

[15] MaleK A.M., AlPer S.L., Izumo S., Hemodynamic shear stress and its role in atherosclerosis, JAMA, 1999, 282, 20352042, DOI: 10.1001/jama.282.21.2035.

[16] Paszenda Z., Marciniak J., Będziński R., Rusiński E., SMOLNICKI T., Biomechanical characteristics of stent-coronary vessel system, Acta Bioeng. Biomech., 2002, 4 (1).

[17] Raben J.S., Morlacchi S., Burzotta F., Migliavacca F., VLACHOS P.P., Local blood flow patterns in stented coronary bifurcations: An experimental and numerical study, J. Appl. Biomater. Funct. Mater., 2015, 13, DOI: 10.5301/ jabfm.5000217.
[18] Rigatelli G., Zuin M., Fong A., Tai T.T., Nguyen T., Left main stenting induced flow disturbances on ascending aorta and aortic arch, J. Transl. Intern. Med., 7, 22-28, DOI: 10.2478/ jtim-2019-0005.

[19] Szabadits P., Puskas Z., Dobranszky J., Flexibility and trackability of laser cut coronary stent systems, Acta Bioeng. Biomech., 2009, 11 (3).

[20] TOMASZEWSKI M., SyBILSKI K., BARANOWSKI P., MAŁACHOWSKI J., Experimental and Numerical Flow Analysis Through Arteries With Stent Using Particle Image Velocimetry And Computational Fluid Dynamics Method, Biocybern. Biomed. Eng., 2020, DOI: 10.1016/j.bbe.2020.02.010.

[21] Tomaszewski M., Baranowski P., MaŁachowski J., DAMAZIAK K., BuKaŁA J., Analysis of artery blood flow before and after angioplasty, AIP Conference Proceedings, 2018, DOI: $10.1063 / 1.5019068$.

[22] WASILEWSKI J., KILJAŃSKI T., MiSZALSKI-JAMKA, Role of shear stress and endothelial mechanotransduction in atherogenesis, Kardiol. Pol., 2011, 69, 717-720.

[23] Wei L., Leo H.L., Chen Q., Li Z., Structural and Hemodynamic Analyses of Different Stent Structures in Curved and Stenotic Coronary Artery, Front. Bioeng. Biotechnol., 2019, 7, 1-13, DOI: 10.3389/fbioe.2019.00366.

[24] Williams A.R., Koo B.-K., Gundert T.J., FitzGerald P.J., LADisA J.F., Local hemodynamic changes caused by main branch stent implantation and subsequent virtual side branch balloon angioplasty in a representative coronary bifurcation, J. Appl. Physiol., 2010, 109, 532-540, DOI: 10.1152/ japplphysiol.00086.2010. 